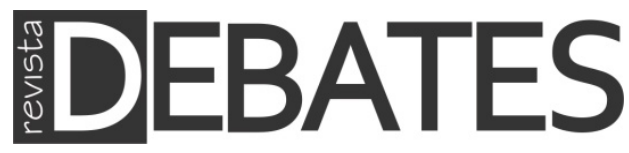

\title{
Indignação em rede: mudanças e continuidades na socialização política juvenil a partir de Junho de 2013
}

\author{
Network indignation: changes and continuities in juvenile political \\ socialization from June 2013
}

\section{Conrado Pereda Minucelli Rosana Katia Nazzari}

\section{Resumo}

O artigo apresenta resultados de investigaçóes longitudinais comparadas de socialização política juvenil entre os anos de 2012 e 2015, tendo como referencial os movimentos em rede de Junho de 2013 em uma cidade distante dos grandes centros de mobilização política. Tecem-se análises acerca da relação entre os novos arranjos de organização dos movimentos sociais, a inserção e crescimento do uso das redes sociais na mediação política e cultural da juventude com a arena política e suas possíveis consequências nas mudanças e continuidades no processo de socialização política de adolescentes e jovens do Ensino Médio público. Por meio da aplicação de survey, no município de Cascavel, no Estado do Paraná, evidenciou-se uma gradual tendência de abertura paradigmática das instituições sociais tradicionais na participação social dos jovens, em consonância com as características multimodais que incentivam a participação política por meio das redes sociais.

\section{Palavras-chave}

Movimentos em Rede; Juventudes; Junho de 2013.

\begin{abstract}
The article presents the results of comparative longitudinal research of juvenile political socialization between the years 2012 and 2015, having as a reference the web movements of June 2013 in a city away from the big centers of political mobilization. It analyses the relation among the new organizational arrangements of social movements, the insertion and growth of social network use in the political and cultural mediation between the youth with the political arena and its possible consequences on the changes and continuities in the process of political socialization of teenagers and young adults of public High School. Through the usage of surveying in the municipality of Cascavel, State of Paraná, it was evidenced a gradual tendency of paradigmatic opening of traditional social institutions in the social participation of young people, according to the multimodal characteristics that incentive political participation through social networks.
\end{abstract}

\section{Keywords}

Network Movements; Youth; June 2013. 


\section{Introdução}

Este artigo nasce da necessidade de reflexão sobre as formas atuais de interseção entre as juventudes e a arena política brasileira, expressas principalmente pelo advento e crescente consolidação dos ambientes virtuais na vida social dos indivíduos ${ }^{1}$. Neste bojo, os conhecidos ciclos de protestos de Junho de 2013 evidenciaram um profícuo lócus de análise dos diversos fatores que possam influenciar nas mudanças e continuidades dos processos de socializaçáo política das juventudes no contexto brasileiro e, especialmente, nas cidades do interior do país.

O Democracy Index 2014 (Índice de Democracia 2014), elaborado pela Economist Intelligence Unit (EIU) ${ }^{2}$, que avalia a evolução de processos eleitorais latino-americanos e mundiais, mostra que o Brasil é o quinto país da amostra com maior grau de participação popular nas eleiçóes, liberdades civis, pluralismo no âmbito partidário e transparência no processo eleitoral na América Latina, atrás de países como Uruguai, Costa Rica, Chile e Jamaica, ganhando apenas a $44^{a}$ posição nos países considerados democráticos, dentre os 165 considerados livres. Apesar de subir uma posição em relação ao relatório de 2006, o Brasil ainda é considerado pelo índice como uma "democracia falha", situação idêntica à de outros 51 países ou regimes políticos que governam $35,5 \%$ da população mundial.

Em conjunto com a teoria culturalista desenvolvida no país, os índices e a literatura especializada indicam que a cultura política brasileira e latino-americana se cristalizou na baixa participação dos cidadãos nos assuntos comunitários e da esfera pública; porém, e para além da participação meramente eleitoral, nada abalou mais as análises sociais e políticas latino-americanas e brasileiras que as mobilizaçóes populares de Junho de 2013, momento em que, dotada de uma organização política nova, multifacetada, descentralizada e de diversas pautas, uma camada significativa da população brasileira engendrou protestos de rua massificados.

No âmbito da reflexão científica, pela proximidade dos eventos e suas rápidas dinâmicas, este fenômeno ainda não ganhou uma ou mais publicaçóes de peso e tampouco se espera, no mais curto espaço de tempo, compreender quais serão os caminhos que tomará, porém, caminha a largos passos para ser compreendido por

\footnotetext{
1 Os dados aqui apresentados são fruto da dissertação de Mestrado defendida no Programa de Pósgraduação em Ciências Sociais da Universidade Estadual do Oeste do Paraná (Unioeste), orientada pela Profa. Dra ${ }^{\text {a }}$ Rosana Katia Nazzari e avaliada pelos membros da banca Prof. Dr. Marcello Baquero e Prof. Dr. Geraldo Magella Neres.

${ }^{2} \mathrm{O}$ Economist Intelligence Unit Democracy Index é compilado pela revista inglesa The Economist.
} 
meio das múltiplas características que o formaram e dos discursos e práticas que lhe conferiram inventividade e autenticidade.

Percebeu-se, na literatura que tem se debruçado sobre isso, que estas mobilizaçóes, chamadas por Castells (2013) de movimentos em rede, definiram e abriram caminhos para se pensar os movimentos sociais a partir de uma característica específica: a conectividade cidadã. A conexão cibernética e, portanto, tecnológica, de ambiçôes, indignaçôes e esperanças com intuitos e vertentes ideológicas variadas, desde a derrubada do regime político à exigência de novas formas de democracia e participação cidadã fizeram parte das reivindicações em rede.

Neste sentido, como afirma Lévy (1999), o ciberespaço em si se tornou uma ferramenta essencial para a democracia e para o aprimoramento de uma inteligência coletiva $^{3}$ dos cidadáos. Além de poderem ser colocadas a serviço de regióes e cidades com vulnerabilidade social e servir como um instrumento de desenvolvimento social, como forma de se constituir cidades e democracias eletrônicas, ele facilitou a troca de experiência, de saberes, a ajuda mútua, um acréscimo na participação dos cidadãos nas decisôes políticas e, por fim, uma conjugação de forças para o avanço da cidadania.

Junho de 2013 mostrou-se avesso à hierarquização política e à verticalização da organização dos movimentos sociais experimentadas até entấo como exemplos clássicos de mobilização política. Seguindo o mote político do Movimento Passe Livre (MPL), sufocou o Poder Executivo, protagonizando um grande número de atos públicos em um curto espaço de tempo, parando as cidades para, enfim, os indivíduos terem sua parcela de protagonismo político em detrimento a qualquer tipo de poder institucionalizado (TATAGIBA, 2014).

De modo geral, podemos compreender Junho de 2013, assim como as Diretas Já e os Caras Pintadas, como manifestaçóes amplas da cidadania e/ou dos "indignados". Isto significa dizer que as características de ambos os ciclos de protestos envolvem:

\footnotetext{
${ }^{3} \mathrm{O}$ conceito de Inteligência Coletiva é utilizado por Pierre Lévy para designar formas de os seres humanos pensarem e compartilharem conhecimentos, por meio de ferramentas mecânicas, como por exemplo, a internet. Com ela, os próprios usuários geram seu conteúdo e seu próprio tipo de interatividade.
} 
agregados de múltiplos coletivos no espaço público, com reivindicaçôes conjunturais, mas, frequentemente, com protestos politicamente heterogêneos, diversificados e podendo conter antagonismos políticos explicitados ou não, e mobilizados, especialmente, através das redes sociais e/ou virtuais (SCHERER-WARREN, 2014, p. 14).

Além da autonomia, da horizontalidade, das múltiplas formas de mobilizaçáo, da mescla de luta política territorial local-global de suas presenças e de suas pautas, da espontaneidade e da cooperaçáo e solidariedade entre os manifestantes e com as variadas causas sociais que se apresentaram em diferentes contextos, a capacidade de autorreflexáo dos movimentos em rede os fizeram se caracterizar como padrôes emergentes de possíveis açôes políticas aos movimentos sociais.

Por meio de toda esta realidade que concerne a democracia brasileira, os movimentos em rede emergentes, as novas experimentaçôes democráticas e a cultura e socialização política da juventude, mostrou-se interessante para este estudo selecionar a cidade de Cascavel, Estado do Paraná, que reuniu mais de 10 mil pessoas no primeiro maior protesto em 13 de junho e 5 mil pessoas no segundo, no dia 15 de junho. Escolheu-se este recorte territorial para, acima de tudo, adequar a viabilidade da pesquisa; porém, é certo que, se analisados outros contextos semelhantes (cidades do interior do país com características sociais parecidas), os mesmos resultados podem se apresentar.

No caso que aqui se apresenta, a participação política da juventude foi expressiva e consolidou uma categoria de experimentação democrática histórica no município, nunca antes vista nos mais de 60 anos de história emancipada da cidade.

O eixo em que orbita o problema desta pesquisa, portanto, é: “a experimentação democrática dos protestos massificados, a criação de comunidades virtuais democráticas e outras características dos Movimentos Sociais na era da internet fizeram variar, em curto prazo, os modos de socialização e a Cultura Política juvenil em Cascavel/PR?”.

Se objetiva demonstrar os elementos de cultura e socialização política juvenil em Cascavel entre os anos de 2012 e 2015 para, utilizando-se das experimentaçóes democráticas vivenciadas em 2013, compreender o comportamento das atitudes políticas da juventude em relação aos movimentos em rede.

Propôs-se, então, para este estudo, um desenho de pesquisa que levou em conta os seguintes aspectos: 1) a caracterização geral do público de pesquisa: a juventude do município de Cascavel e, em especial, os estudantes do Ensino Médio 
público e suas percepçóes e relaçóes com os movimentos em rede e os protestos de Junho de 2013 e 2) a análise de dados clássicos e específicos da cultura e socialização política do público do estudo, demonstradas no que se segue.

\section{Formação e possibilidades das comunidades virtuais de mobilização politica}

Quando objetos de reflexão, as reunióes e mobilizaçóes virtuais por pautas diversas são importantes problemáticas quando se pensa sua posterior ação política na realidade. A possibilidade de transformação das reuniôes virtuais se transformarem em reuniōes físicas foi respaldada por teóricos como Howard Rheingold, William Mitchell e Sherry Turkle, que viam nas comunidades virtuais novas formas de vida urbana e de sociabilidade, permitindo novas construçóes e expressốes identitárias e desempenhos diferenciados de papéis sociais.

A construção do conceito de comunidade virtual é facilmente confundida com uma realidade social idealizada ou ilusória, visto que o acesso às condiçóes reais da vida social seria limitado pela pequena gama de sensibilidade social que as redes comportam, dadas e vividas em condiçóes reais diferentes das colocadas no mundo virtual. Porém, como comunidades virtuais e comunidades físicas não precisam, necessariamente, serem consideradas opostas, Castells (1999) afirma que a constituição e consolidação de comunidades virtuais são apenas outra forma possível do conceito de comunidade, com dinâmicas e leis singulares, que podem interagir com outras formas.

Desta forma, os vínculos e práticas sociais que se formam nas redes virtuais são dimensões possíveis, especializadas e diversificadas de satisfação de interesses sociais também específicos e diversos, em que

tanto off-line quanto on-line, os laços fracos (da modernidade) facilitam a ligação das pessoas com diversas características sociais, expandindo assim a sociabilidade para além dos limites socialmente definidos do autorreconhecimento. Nesse sentido, a Internet pode contribuir para a expansão dos vínculos sociais numa sociedade que parece estar passando por uma rápida individualização e uma ruptura cívica (CASTELLS, 1999, p. 445).

Esta desvinculação social crescente teria, nos vínculos virtuais, um refúgio ou uma possibilidade de vínculos sociais mínimos para as pessoas que, ao contrário disto, viveriam apenas vidas sociais limitadas se, apenas na vida física, sobrevivessem 
somente com os vínculos cada vez mais espacialmente e temporalmente dispersos da sociedade contemporânea.

De todo modo, caberia às Ciências Sociais estudar o fenômeno da virtualização das comunidades como uma produção e reprodução cultural. Partindo deste pressuposto, este novo tipo emergente de comunidade não seria apenas uma espécie de indução à realidade virtual, mas a construção de uma realidade virtual, pois toda realidade cultural advém da formação, assimilação e reprodução de símbolos formadores daquela realidade. Em outras palavras, "a realidade, como é vivida, sempre foi virtual porque sempre é percebida por intermédio de símbolos formadores da prática com algum sentido que escapa à sua rigorosa definição semântica" (CASTELLS, 1999, p. 459).

O novo sistema de comunicação humana que se coloca, portanto, proporciona, além da reprodução cultural da vida física nas comunidades virtuais, a inclusão e uma maior abrangência das expressóes culturais, sejam individuais ou coletivas. Dentre os fatores que as caracterizam, tem-se que a diversificação, a multimodalidade e a versatilidade deste sistema são capazes de lidar com valores, com a moral, com o imaginário e também com os conflitos sociais, gerando uma queda de importância do poder simbólico de instituiçóes tradicionais presentes fora das comunidades virtuais como a religiáo, a autoridade, os valores tradicionais, as ideologias políticas e a autoridade carismática.

Esta correlação de forças entre o tradicional e o emergente gera, portanto, uma espécie de disputa social não mais inédita na história da humanidade, que se expressa na tentativa de adaptação da liderança carismática, da moralidade e dos valores ao novo contexto social da informação, podendo inverter a lógica de que, por exemplo, são os fluxos de poder que movem a política ou qualquer outro âmbito da vida social, mas sim onde é o poder dos fluxos da informaçáo que exercem força maior na determinaçáo da realidade social.

Assim, a virtualidade das relaçôes sociais, além de não ser um produto artificial, criado apenas para atender demandas isoladas do sistema social, é igualmente geradora de práticas reais, justamente por ser reflexo destas. Desta forma, a geraçáo de comunidades virtuais de exercício da democracia ou da participação geram os laços de solidariedade necessários para a açáo política concreta na medida em que esta é necessária, debatida e decidida pelos indivíduos e grupos online.

Elas estâo, enfim, diretamente relacionadas ao modo como a socialização política e a sociabilidade contemporâneas existem e se expressam nas atitudes, comportamentos e orientaçóes gerais dos indivíduos. São expressóes de uma 
sociedade em rede que, agora organizadas no espaço democrático, deram nascimento aos movimentos sociais contemporâneos e sua interlocução com a tecnologia e à conectividade cidadã.

\section{Caracterização e métodos}

Para a observação da variação ou não da Cultura Política juvenil em Cascavel/PR, fez-se teste quantitativo com aplicação de questionários compostos de entrevistas semi-estruturadas para a população juvenil de 13 a 19 anos de idade faixa etária selecionada para melhor apreensão dos modos de socialização política - de estudantes de escolas públicas estaduais do município, em uma amostra selecionada definitiva de 503 entrevistados.

Utilizou-se como fundamento para coleta destes tipos de perguntas alguns modelos de questóes aplicadas por instituiçóes como o Latinobarômetro, uma pesquisa de captação de percepções, satisfações e análises de opinião pública com referência mundial na produção de pesquisas na área de Ciência Política ${ }^{4}$.

Já para testar as questóes relativas à opiniáo pública sobre os protestos, seguiram-se as pesquisas realizadas durante os movimentos em rede que ficaram conhecidos por Occupy Wall Street, nos Estados Unidos da América, colhidas por órgãos como o Ipsos/Reuters, pesquisa CBS/New York Times, pesquisa NBC News/Wall Street Journal e Instituto Gallup, todas utilizadas por Castells (2013).

A escolha do número de questionários aplicados por conglomerados regionais levou em consideração a distribuição populacional do município, juntamente com o número de escolas disponíveis para aplicaçáo, conforme autorização do Núcleo Regional de Educação. Foram participantes desta pesquisa 12 escolas e 24 turmas de Ensino Médio ( $1^{\circ} s, 2^{\circ} s$ e $3^{\circ} s$ anos), onde se realizaram, com apoio das direçôes e equipes pedagógicas, sorteios aleatórios para a participação dos estudantes, objetivando retirar a amostra mais fiel do público da pesquisa.

De acordo com o sistema oficial de consulta às escolas paranaenses 5 , 7.800 estudantes constituíam o universo da população escolhida. Este sistema eletrônico é conectado em tempo real com a situação de matrícula dos estudantes nos estabelecimentos de ensino, o que permite fidedignidade com o número de estudantes. Os números utilizados para a montagem dos dados foram acessados em setembro de 2013, pelo próprio sítio do sistema.

\footnotetext{
${ }^{4}$ Disponível em: http://www.latinobarometro.org.

${ }^{5}$ Disponível em www.consultaescolas.pr.gov.br, sítio oficial do Governo do Estado do Paraná.
} 
54 | Conrado Pereda Minucelli e Rosana Katia Nazzari

Para a amostra, o cálculo originou-se na pré-determinação proporcional de um número de questionários semelhante às pesquisas anteriores de Socialização e Cultura Política juvenil em Cascavel/PR, realizadas em 2006 e 2012, respectivamente pelas Professoras Doutora Rosana Katia Nazzari e Mestra Thaís Damaris da Rocha Thomazini. Este número se aproxima do utilizado como primeira aproximaçáo do tamanho da amostra para o cálculo do erro amostral, ou seja, 500 unidades.A pesquisa conta com um erro amostral de $5 \%$ e confiança de $95 \%$, calculada sobre os parâmetros estatísticos expostos por Barbetta (2002).

No que concerne à dimensão qualitativa, consideraram-se os conceitos clássicos da ciência política como cultura política, Socialização Política, Participação democrática e Movimentos sociais em suas características contemporâneas de rede, como conceitos em que orbitam as lógicas das atitudes políticas do público da pesquisa.

As variáveis são as mesmas já consagradas pela Ciência Política clássica brasileira e mundial: escolaridade dos jovens e de seus genitores, renda familiar, participação em eventos e atividades, participação em eleiçôes, grau de informação política, confiança nas instituições sociais e confiança no sistema político (ALMOND e VERBA, 1965; ALMOND e POWELL JR., 1972; SARTORI, 1994; MOISÉS, 2010).

Para uma avaliação longitudinal numa perspectiva histórica, entre a pesquisa culminada em 2012 e esta, culminada em 2015, o método comparativo buscou semelhanças e diferenças entre os fatos, abordando duas séries de natureza análoga tomadas dos meios sociais pesquisados, a fim de verificar o que é e o que não é comum em ambos (ALMOND e POWELL JR., 1972; BILL e HARDGRAVE JR., 1973).

O intuito da conjugação destas duas dimensôes da pesquisa é estabelecer uma análise de algumas variáveis da cultura e socialização política e da percepção, informaçáo, opiniáo e participação dos adolescentes e jovens nos movimentos em rede de Junho de 2013 na cidade. São elas: a) perfil socioeconômico dos estudantes de Ensino Médio público da cidade de Cascavel/PR; b) percepção e satisfação com a democracia e suas nuances na cidade de Cascavel e no Brasil; c) participaçáo social e política em suas dimensóes comunitárias e/ou institucionais representativas; d) 
percepção em relação à confiança política ${ }^{6}$ interpessoal e institucional; e) participação, informaçáo e sentimentos em relação às características dos movimentos em rede e sobre os protestos de Junho de 2013.

No desenvolvimento de cada um destes subitens do estudo, realiza-se uma análise em separado dos casos de questionários respondidos por estudantes que participaram dos protestos na cidade de Cascavel/PR, tendo como objetivo evidenciar as possíveis diferenças entre este subgrupo e a amostra geral da pesquisa e compreender quem são os jovens que saíram às ruas neste contexto em rede.

Além de se abordar estes resultados inéditos, objetiva-se também estabelecer uma análise comparativa com pesquisa de Socialização e Cultura Política imediatamente anterior a Junho de 2013, realizada por Thomazini (2012), a fim de verificar se a experimentaçáo democrática dos protestos de rua e o contexto social dos movimentos em rede fizeram oscilar ou não as variáveis de Socialização e Cultura Política no município.

\section{Mudanças e continuidades no processo de socialização politica juvenil}

O primeiro bloco de questóes disponível para resposta dos entrevistados contemplou um delineamento do perfil socioeconômico dos jovens estudados.

Tabela 1 - Cruzamento Idade X Sexo do público da pesquisa (em \%)

\begin{tabular}{c|c|c|c|c|c|c|c|c}
\hline \multicolumn{2}{c|}{} & \multicolumn{7}{c}{ Idade } \\
\cline { 3 - 9 } \multicolumn{2}{c|}{} & 13 anos & 14 anos & 15 anos & 16 anos & 17 anos & 18 anos & 19 anos \\
\hline \multirow{3}{*}{ Sexo } & Fem & 0,0 & 1,2 & 5,4 & 23,9 & 22,9 & 3,0 & 2,4 \\
\cline { 2 - 9 } & Mas & 0,4 & 1,0 & 6,4 & 16,3 & 11,2 & 3,6 & 2,4 \\
\hline
\end{tabular}

$\mathrm{n}=503$

Fonte: Elaboração dos autores.

Observa-se, pela Tabela 1, que o maior número de entrevistados concentrase entre a faixa etária entre 16 e 17 anos, com uma predominância de pessoas do sexo feminino $(58,8 \%)$, destacando que $23,9 \%$ dos entrevistados são compostos por jovens mulheres de 16 anos de idade. Na pesquisa realizada por Thomazini (2012), o

${ }^{6} \mathrm{O}$ conceito de confiança política é entendido aqui como um dos mecanismos de geração de solidariedade entre os indivíduos de uma sociedade, que promove a cooperação e a legitimação das decisôes coletivas e das estruturas democráticas de poder (MISZTAL, 1998). 
número de mulheres somava $56,6 \%$ e também possuía, em sua maioria, 16 anos. As pessoas do sexo masculino somam $41,2 \%$ e estáo concentradas também entre 16 e 17 anos.

Quanto à escolaridade dos pais, notou-se uma relevante semelhança de formação entre as mulheres e os homens. As mães e pais, predominantemente, frequentaram a escola até o Ensino Fundamental (31,81\% das mães e 32,01\% dos pais), com números consideráveis também de concluintes do Ensino Médio (27,44\% das mães e $26,44 \%$ dos pais).

De acordo com Nazzari (2006), os estudos de socialização e cultura política da juventude têm demonstrado uma contradição entre a baixa escolaridade dos pais e mães e a expansão crescente das instituiçôes de ensino superior no Brasil. Tal variável é fundamental para estes estudos, pois permite associaçôes de proporcionalidade com os níveis de informação política, participação, adesão e legitimação do sistema democrático, além de se constituir como elemento necessário para a elevação dos índices de capital social nas comunidades.

No tocante à preferência por formas determinadas de governo, a pesquisa mostrou que $47,12 \%$ dos entrevistados preferem a democracia a qualquer outra forma de governo, 19,68\% acham que, em alguns casos, um governo autoritário pode ser preferível, $16,1 \%$ deixaram a questão sem resposta, $14,51 \%$ afirmaram não saber responder e $2,58 \%$ dizem que tanto faz ser ou não um governo democrático.

Destacou-se, nesta questão, o elevado percentual de jovens que afirmam não saber responder à questáo ou a deixaram sem marcaçáo de resposta, evidenciando que o conhecimento sobre as formas de governo e suas características ainda é frágil entre os jovens estudados. A preferência por governos autoritários em determinados casos também não pode ser desconsiderada: dos 503 entrevistados, 99 assinalaram esta afirmação.

Explicativo disto, como afirma Baquero \& Keil et al. (2004) a cultura política autoritária, desenvolvida historicamente no Brasil e na América Latina, contribuiu significativamente para que houvesse uma reproduçáo longitudinal de traços autoritários na forma como os jovens encaram a política, ou seja, a forma autoritária de conduzir as mudanças ou permanências de aspectos do sistema político cristalizou este traço e permite que ele se reproduza.

Contudo, a maioria ainda se constitui de jovens que preferem formas de governo democráticos em detrimento de qualquer outra possibilidade, o que mostra a disposição majoritária da juventude em fomentar a construção de formas de visibilidade que percorram caminhos democráticos, índices que coincidem 
longitudinalmente com as pesquisas realizadas por Baquero, Nazzari, Schmidt, Thomazini e outros.

Por sua vez, no subgrupo de participantes dos protestos de Junho de 2013 na cidade, os números seguiram praticamente a mesma média dos outros respondentes: $51,9 \%$ preferem as formas democráticas de governo, 20,8\% preferem governos autoritários em determinados casos e 2,8\% dizem que tanto faz ser ou não um governo democrático. Os que não souberam responder ou não assinalaram a questão somam $24,5 \%$.

Percebe-se que há um aumento da preferência por governos autoritários e também no número de entrevistados que não responderam neste subgrupo de análise, o que caracteriza que metade dos participantes dos protestos possuem uma definiçáo frágil do que seja o processo político autoritário e democrático, também reproduzindo as formas autoritárias de pensar da cultura política brasileira.

Perguntados acerca de sua participação social e comunitária, os resultados mostraram um acréscimo importante nos índices, demonstrados pela Tabela 2 a seguir, que já conta com a porcentagem de apariçóes positivas ou não de cada evento e uma comparação com os dados coletados em 2012, no intento de verificar mudanças ou manutenções nos padrôes atitudinais em relação à participação, com destaque em negrito para as mais relevantes:

Tabela 2 - Porcentagem de participação em atividades ou instituiçôes comunitárias, comparativo a $2012(\mathrm{em} \%)$

\begin{tabular}{c|c|c|c|c}
\hline & \multicolumn{2}{|c|}{$2012(\mathrm{n}=456)$} & \multicolumn{2}{c}{$\mathbf{2 0 1 5}(\mathrm{n}=503)$} \\
\hline Eventos/Atividades & Sim & Náo & Sim & Náo \\
\hline Conselho de Classe na escola & $\mathbf{1 4}$ & 86 & $\mathbf{2 2 , 5}$ & 77,5 \\
\hline Grêmio Estudantil & 9,4 & 90,6 & 18,7 & 81,3 \\
\hline Associaçóes de moradores do bairro & 4,2 & 95,8 & 9,3 & 90,7 \\
\hline Grupo de jovens religioso & $\mathbf{3 7 , 7}$ & 62,3 & 56,7 & 43,3 \\
\hline Protestos e passeatas & $\mathbf{1 2 , 3}$ & 87,7 & $\mathbf{3 4}$ & $\mathbf{6 6}$ \\
\hline Partidos Políticos & 2,6 & 97,4 & 3,6 & 96,4 \\
\hline Sindicatos & 1,8 & 98,2 & 3,8 & 96,2 \\
\hline
\end{tabular}

Fonte: Elaboração dos autores. 
Os números apresentam aumento de participação em todas as atividades ou instituições de 2012 para 2015, com destaque para o aumento de participação em protestos e passeatas, grupo de jovens religioso - que é o único item que ultrapassou $50 \%$ de participação - e em conselhos de classe na escola. Os aumentos assinalam um fomento na participaçáo política e comunitária dos jovens de Cascavel/PR e também um maior incentivo à participação ou relativização de paradigmas pelas instituiçóes sociais tradicionais, como a religiáo e a escola.

Apesar de os números ainda indicarem um descrédito considerável nas instituiçóes e grupos sociais para a participação, o aumento nos índices parece apontar um crescimento dos estoques de capital social entre os estudantes do Ensino Médio público de Cascavel. São estes níveis de participação que permitem que a organização global da sociedade coopere no sentido de desenvolver ou ampliar projetos de crescimento dos bens públicos e de felicidade coletiva, além de pertencimento, legitimação e adesão à democracia (PUTNAM, 2006).

Destaca-se também que, no contexto dos movimentos em rede, a onda globalizante das TIC's funciona como facilitadora, mesmo que de forma temporária e inconstante, promovendo a discussão online e a criação de fóruns públicos de debate e decisão, que constituem um importante instrumento de incentivo à participaçáo em protestos e, na medida em que enxergam expressão popular, crescem de maneira virtuosa até terminarem em suas próprias práticas. Conforme Castells (2013), o interesse do público dos protestos parece estar na mensagem causada pelas mobilizaçóes e não necessariamente pelos seus resultados imediatos, ou, em outras palavras, na esperança da mudança do sistema político e econômico.

Quanto a atividades desenvolvidas entre 2013 e 2014, fora do espectro eleitoral, temos um quadro relativamente semelhante: 
Tabela 3 - Porcentagem de participação em atividades referentes à política entre 2013 e 2014 em comparativo a 2012 (em \%)

\begin{tabular}{|c|c|c|c|c|}
\hline & \multicolumn{2}{|c|}{$\begin{array}{c}2015 \\
(\mathrm{n}=503)\end{array}$} & \multicolumn{2}{|c|}{$\begin{array}{c}2012 \\
(n=456)\end{array}$} \\
\hline Eventos/Atividades & Sim & Náo & Sim & Năo \\
\hline $\begin{array}{l}\text { Li reportagens em jornais ou revistas sobre assuntos relacionados à } \\
\text { política }\end{array}$ & 50,9 & 49,1 & 46,9 & 53,1 \\
\hline $\begin{array}{l}\text { Participei de associaçóes ou grupos para resolver problemas do bairro } \\
\text { ou da cidade }\end{array}$ & 7,4 & 92,6 & 6,8 & 93,2 \\
\hline Fiz pedidos para políticos & 7,6 & 92,4 & 8,8 & 91,2 \\
\hline Acompanhei notícias sobre política pela internet e nas redes sociais & 55,3 & 44,7 & 15,5 & 84,5 \\
\hline $\begin{array}{l}\text { Conversei com algum vereador sobre problemas da minha } \\
\text { comunidade }\end{array}$ & 8,9 & 91,1 & 9,6 & 90,4 \\
\hline $\begin{array}{l}\text { Conversei com professores, coordenadores ou diretores sobre os } \\
\text { problemas da escola }\end{array}$ & 41,4 & 58,6 & 34,4 & 65,6 \\
\hline
\end{tabular}

Fonte: Elaboração dos autores.

A partir dos dados apresentados na Tabela 3, pode-se perceber igualmente um relativo acréscimo nos estoques de capital social da juventude entrevistada. Por um lado, o aumento de atividades como ler reportagens sobre política e conversar com professores, coordenadores e diretores sobre os problemas da escola aponta o mesmo verificado anteriormente, ou seja: as instituiçóes tradicionais tendem, neste contexto, a investir na abertura democrática para participação dos jovens e, do mesmo modo, a mídia parece atrair mais o olhar dos estudantes sobre o mundo político, relatando, com frequência, a sua importância e, além disso, buscando traduzir informaçóes antes inacessíveis ao público jovem.

Por outro lado, verifica-se que os canais de comunicaçáo com a institucionalidade democrática, de fato, perdem cada vez mais relevância e eficácia. Isto é evidenciado no fato de as duas únicas alternativas com baixa no número de realizaçóes serem, justamente, duas dimensôes da mediação entre os cidadãos e o sistema representativo: a conversa com vereadores e o pedido para políticos. Evidencia-se, assim, que a desconfiança nos procedimentos do sistema democrático, através dos representantes políticos, forma uma considerável barreira para o acesso e a disposiçáo em acessar os mecanismos democráticos de controle de mandatos e de controle social por parte dos jovens entrevistados.

Afora estas constataçóes, o relevante destaque continua sendo o crescente uso das redes sociais e da internet para a informação política dos jovens. Na pesquisa 
de 2012, percebeu-se que, quando perguntados especificamente sobre a época de eleiçóes, mais jovens responderam que se informavam pela internet, em comparação com os números de informação com uso das redes fora do espectro eleitoral.

$\mathrm{Na}$ pesquisa de 2015 , verifica-se que os números se repetem precisamente nos dois momentos, o que demonstra que a tendente consolidação das redes sociais e da internet na arena política não atinge agora apenas os períodos eleitorais e nem somente aqueles jovens que querem usar a internet apenas para se informar sobre o voto, mas sim todas as dimensóes cotidianas da política, que envolvem as situaçóes políticas e suas influências na vida de cada indivíduo ou grupo social.

Paralelo a isto e em relação às variáveis específicas para verificação da confiança política e interpessoal, se estimulou os entrevistados a dizerem se confiavam totalmente, até certo ponto, náo confiavam ou se náo sabiam responder se confiavam nas instituiçóes, pessoas e representantes políticos abaixo. A Tabela 4 que segue demonstra os graus de confiança e desconfiança de forma comparativa entre 2012 e 2015, indicando também os dados relativos ao subgrupo de participantes dos protestos nos itens "Governo Federal", "Governo Municipal", "Partidos Políticos", "Igreja", "Família", "Escola”, "Mídia” e "Amigos", em negrito: 
Tabela 4 - Confiança institucional e interpessoal comparada no tempo (em \%)

\begin{tabular}{|c|c|c|c|c|c|c|c|c|}
\hline \multirow[t]{2}{*}{ Você confia? } & \multicolumn{2}{|c|}{$\begin{array}{c}\text { CONFIO } \\
\text { TOTALMENTE }\end{array}$} & \multicolumn{2}{|c|}{$\begin{array}{c}\text { CONFIO ATÉ } \\
\text { CERTO } \\
\text { PONTO }\end{array}$} & \multicolumn{2}{|c|}{$\begin{array}{c}\text { NÁO } \\
\text { CONFIO }\end{array}$} & \multicolumn{2}{|c|}{$\begin{array}{c}\text { NÃO SEI } \\
\text { RESPONDER }\end{array}$} \\
\hline & 2012 & 2015 & 2012 & 2015 & 2012 & 2015 & 2012 & 2015 \\
\hline \multirow{2}{*}{ Governo Federal } & \multirow{2}{*}{1,8} & 5,2 & \multirow{2}{*}{53,3} & 47,3 & \multirow{2}{*}{34,2} & 35 & \multirow{2}{*}{10,7} & 12,5 \\
\hline & & 5,7 & & 54,7 & & 34 & & 5,7 \\
\hline Governo Estadual & 2,6 & 4,2 & 53,1 & 45,1 & 33,3 & 39,2 & 11 & 11,5 \\
\hline \multirow{2}{*}{ Governo Municipal } & \multirow{2}{*}{4,2} & 2,8 & \multirow{2}{*}{52,6} & 44,1 & \multirow{2}{*}{32,7} & 41,6 & \multirow{2}{*}{10,5} & 11,5 \\
\hline & & 2,8 & & 48,1 & & 42,5 & & 6,6 \\
\hline Deputados Estaduais & 1,5 & 1,8 & 43,4 & 39,6 & 43,2 & 48,3 & 11,8 & 10,3 \\
\hline Vereadores & 2 & 0,6 & 42,5 & 35,8 & 45,2 & 53,3 & 10,3 & 10,3 \\
\hline \multirow{2}{*}{ Partidos Políticos } & \multirow{2}{*}{2} & 1 & \multirow{2}{*}{38,2} & 36,4 & \multirow{2}{*}{48,9} & 52,5 & \multirow{2}{*}{11} & 10,1 \\
\hline & & 1,9 & & 44,3 & & 49,1 & & 4,7 \\
\hline \multirow{2}{*}{ Igreja } & \multirow{2}{*}{47,1} & 33,8 & \multirow{2}{*}{37,1} & 42,9 & \multirow{2}{*}{11,6} & 14,9 & \multirow{2}{*}{4,2} & 8,4 \\
\hline & & 29,2 & & 49,1 & & 17,9 & & 3,8 \\
\hline \multirow{2}{*}{ Família } & \multirow{2}{*}{79,4} & 72,8 & \multirow{2}{*}{16,4} & 17,9 & \multirow{2}{*}{2,9} & 2,8 & \multirow{2}{*}{1,3} & 6,6 \\
\hline & & 76,4 & & 19,8 & & 0 & & 3,8 \\
\hline \multirow{2}{*}{ Escola } & \multirow{2}{*}{33,8} & 27,4 & \multirow{2}{*}{52,2} & 55,5 & & 9,9 & & 7,2 \\
\hline & & 25,5 & & 62,3 & 11,2 & 6,6 & 2,9 & 5,7 \\
\hline & & 2,4 & & 45,1 & & 45,1 & & 7,4 \\
\hline Midia - IV, jornais & -- & 1,9 & - & 48,1 & -- & 45,3 & - & 4,7 \\
\hline Professores & 30 & 23,5 & 54,6 & 61 & 12,1 & 9,3 & 3,3 & 6,2 \\
\hline & & 27,2 & & 59 & & 7,4 & & 6,4 \\
\hline Amigos & 41,7 & 33 & 49,3 & 60,4 & 7,2 & 2,8 & 1,8 & 3,8 \\
\hline Pessoas & 4,8 & 3,2 & 58,1 & 54,3 & 30,3 & 33,6 & 6,8 & 8,9 \\
\hline
\end{tabular}

$\mathrm{n}=456(2012) ; \mathrm{n}=503(2015)$

Fonte: Elaboração dos autores.

Os índices de confiança política apresentados demonstram continuidades no processo de desconfiança institucional e interpessoal, historicamente tidos na juventude. Porém, como explica Baquero (2004), a desconfiança não pode ser vista apenas pelo viés negativo da falta de integração com o sistema político, mas sim compreendendo que a confiança em excesso é indicador de que a apatia política pode predominar, reduzindo o controle social por parte dos cidadãos sobre o Estado e, por consequência, a eficiência da democracia.

Percebeu-se que, no tocante à confiança nas instituiçóes políticas, os governos e representantes políticos continuam sendo objeto de maior desconfiança por parte dos jovens, com destaque para a desconfiança completa nos vereadores, que atingiu o índice de 53,3\% na categoria "Não confio" e decresceu nas categorias "Confio totalmente" e "Confio até certo ponto". A proximidade dos vereadores com a esfera 
política local poderia ser fator para ter um quadro diferente de confiança; porém, os dados revelaram que é, ao contrário, objeto de desconfiança cada vez maior.

Quando se gira a análise para as instituiçôes sociais tradicionais como a família, a escola e a igreja, se percebe que todas, mas em especial a igreja e a escola, tiveram quedas nos índices de confiança total e aumento de confiança até certo ponto, o que indica que a secularidade ou condição paradigmática destas instituiçôes estão sendo gradativamente questionadas, pois confiar até certo ponto se pode considerar como uma confiança com certas restriçóes, sem uma certeza de que todas as açóes que nelas são praticadas são, de fato, objetos de confiança absoluta.

Ainda assim, a família permanece sendo majoritariamente a instituição mais confiável pelos respondentes, pois $90,7 \%$ demonstraram confiança total ou até certo ponto. Em contraponto, a confiança na igreja passou a ser a menor entre esse tipo de instituição (76,7\%). Mesmo considerando que os níveis são elevados, a confiança na escola foi elevada e na pesquisa de 2015 aparece com 82,9\% de confiança total ou até certo ponto.

Um elemento que se adicionou ao questionário aplicado nesta pesquisa é a confiança na mídia impressa, televisiva ou virtual, que não aparecia em 2012. Segundo os dados, $47,5 \%$ dos entrevistados confiam totalmente ou até certo ponto nas informaçôes, formas ou abordagens da mídia e $45,1 \%$ disseram que não confiam nada.

A grande desconfiança dos jovens na mídia passa muito pelo nível e intensidade de informação a que estáo submetidos os indivíduos e, hoje, principalmente pela substituição gradual do conteúdo televisivo, que era hegemônico, pelo da internet, que questiona e coloca em xeque os conteúdos da mídia clássica.

Como afirma Postman (1999), a televisão redefiniu o que se entende por um consistente juízo político, seja dos jovens ou dos adultos, modificando-o em uma questão estética antes que uma questão lógica, o que provoca a desinformação ou, quando analisada mais a fundo, um rebaixamento intelectual e desconfiança.

Já quando perguntados sobre confiança interpessoal, as quais colaboram também para os níveis de estoque de capital social e cooperação comunitária, constatou-se que os amigos recebem as maiores confianças totais, seguido dos professores e das pessoas no geral. Quando analisados pelo prisma da não confiança, as pessoas recebem o maior descrédito e os professores aparecem em seguida, à frente dos amigos. Ainda de acordo com a Tabela 4, entre o subgrupo de participantes dos protestos de Junho de 2013, pode-se perceber que os mesmos se posicionam mais em relação ao número de respondentes que não souberam responder na pesquisa global. 
Este dado indica que os níveis de confiança interpessoal possuem grande influência nos níveis de informação, participação e debate político da juventude, tendo, nas figuras do professor, da escola em si e dos amigos, diferentes níveis de comunicaçáo, dados os papéis sociais desempenhados por cada pessoa ou instituiçâo no estímulo à participação cidadã.

Objetivando complementar os dados até aqui apresentados, perguntou-se por qual meio os entrevistados mais tinham ouvido falar dos protestos de Junho de 2013. Esses meios foram escolhidos considerando os agentes de socialização como os amigos, família, mídia, escola e as redes sociais ou, ainda, os meios pelos quais a comunicação sobre as manifestaçóes aconteceu.

A Tabela 5 a seguir mostra por quais meios o público da pesquisa se informou sobre os protestos de Junho de 2013 em Cascavel/PR, dividido entre o total de entrevistados e os que participaram das manifestaçôes:

Tabela 5 - Comparativo de meios utilizados para se informar dos protestos (em \%)

\begin{tabular}{l|c|c|c|c}
\hline & \multicolumn{2}{|c|}{$\begin{array}{c}\text { Total } \\
(\mathbf{n = 5 0 3 )}\end{array}$} & \multicolumn{2}{c}{$\begin{array}{c}\text { Participantes } \\
\text { (n=106) }\end{array}$} \\
\hline Por qual meio mais ouviu falar ou se informou? & Sim & Náo & Sim & Náo \\
\hline Pelas redes sociais na Internet & 35 & 65 & 70,8 & 29,2 \\
\hline Conversando com amigos & 16,1 & 83,9 & 19,8 & 80,2 \\
\hline Conversando com a família & 7,8 & 92,2 & 8,5 & 91,5 \\
\hline Assistindo à TV e pelos jornais & 51,3 & 48,7 & 34 & 66 \\
\hline Na escola & 13,1 & 86,9 & 17 & 83 \\
\hline
\end{tabular}

Fonte: Elaboraçáo dos autores.

Neste ponto, mais uma situação se evidencia: a maioria dos jovens que não participou dos protestos se informou pelos meios de comunicação clássicos, ou seja, assistindo à TV e pelos jornais e, em menor medida, se informando nas redes sociais, com amigos e na escola, enquanto os participantes dos protestos utilizaram, de forma significativa $(70,8 \%)$, as redes sociais na internet e, em menor medida, a TV, os jornais e conversando com amigos.

Indica-se, assim, que a participação nos protestos está diretamente relacionada à informação pelas redes sociais e à internet, que passam a se constituir no principal instrumento de mediação entre a organização em rede e a presença física nos protestos. A possibilidade de uma comunicação autônoma, de ser virtual sem filtragem ou seleção, da organizaçáo e avaliaçáo dos movimentos de forma horizontal, 
64 | Conrado Pereda Minucelli e Rosana Katia Nazzari

sem julgamentos de valor ou críticas jornalísticas, formam as bases para que as redes sociais, neste caso, substituíssem os meios de comunicação clássicos na preferência dos manifestantes.

Quando perguntados sobre o quanto ouviram falar dos protestos, a resposta que mais aparece é, em primeiro lugar, a opção "Muito", com 56,6\% das respostas, seguida de "Um pouco" com 23,66\%, "Náo muito" com 8,35\% e "Nada" com 1,19\%. Considerando, assim, que a maioria dos estudantes do Ensino Médio público de Cascavel conheceu, ou ao menos ouviu falar, dos protestos. Possibilita-se, dessa forma, que, mesmo no imaginário dos jovens, tais protestos causaram, ou ainda causam, avaliações, reavaliaçóes e mudanças na forma de perceber a participação política, a organizaçáo em rede e nas redes e o papel da juventude em processos de transformação política.

Já a disputa pela informação, na guerra simbólica produzida pelos meios de comunicação de massa, de forma intensa, provocou também a necessidade de posicionamento dos indivíduos em escalas favoráveis e não favoráveis aos protestos. $\mathrm{A}$ pergunta a seguir pretendeu captar essa informaçáo entre o público da pesquisa e também entre o subgrupo dos participantes das manifestações.

Gráfico 1 - Posição favorável ou contrária aos protestos (em \%)

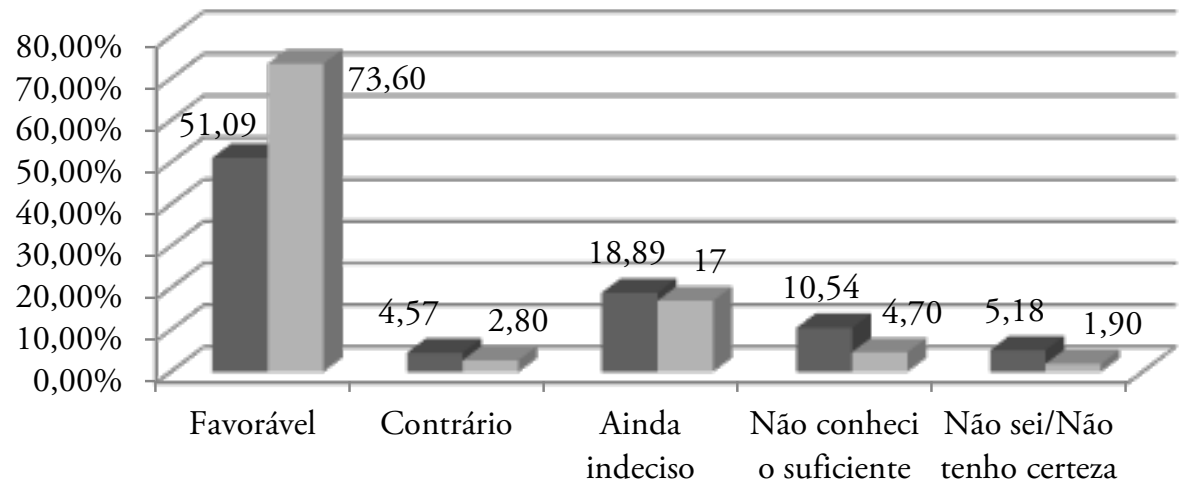

Público total $(\mathrm{n}=503) \square$ Participantes $(\mathrm{n}=106)$

Fonte: Elaboração dos autores.

Percebe-se que, em sua maioria, os jovens mais favoráveis aos protestos são aqueles que participaram das manifestaçôes $(73,6 \%)$, enquanto que os não 
participantes, também em sua maioria, são favoráveis (51,09\%), mas com outras opiniôes mais distribuídas no gráfico.

Neste sentido, buscou-se, também, analisar quais os sentimentos dos entrevistados sobre os protestos. Entre o público total da pesquisa, a maioria classifica seus sentimentos como neutros (46,5\%), enquanto outros $27,2 \%$ classificam-nos como muito positivos ou relativamente positivos, $6,2 \%$ dizem que são negativos ou relativamente negativos, $15,7 \%$ não têm certeza ou não sabe responder e $4,4 \%$ deixaram a questão sem resposta.

Entre o subgrupo de participantes, o quadro mostra mudança. Estes, em sua maioria, disseram que seus sentimentos são muito positivos ou relativamente positivos $(55,7 \%)$, contrastando com 34,9\% de sentimentos neutros, 3,8\% negativos ou relativamente negativos e 5,7\% não souberam responder ou não têm certeza.

Desta forma, perguntou-se se os entrevistados aprovavam ou desaprovavam as formas pelas quais as manifestaçôes foram conduzidas. A maioria do público de pesquisa disse que aprova (36\%); porém, o número de respondentes que desaprovam também é elevado: 30,8\%.

Destaca-se que, neste caso, $29 \%$ dos respondentes não souberam responder, indicando que a dimensão organizativa das mobilizaçôes, a disputa pelos rumos dos movimentos em rede e a disputa simbólica e física pela violência e não violência nos protestos ainda são variáveis que não foram totalmente processadas no imaginário juvenil.

No entanto, entre os participantes das manifestaçóes, a opinião pela aprovação das formas de condução foi mais heterogênea, ou seja, 59,4\% aprovam, $26,4 \%$ desaprovam e $14,2 \%$ ainda não sabiam responder, apontando, novamente, certo grau de influência que a experimentação democrática dos protestos de rua e da organização em rede pode propiciar na tomada de decisóes e posicionamentos dos entrevistados.

Compreendendo que uma das novas características dos movimentos sociais na era da internet é a organização pelas redes sociais e que esta organização pode ser vista de diferentes formas e com diferentes opiniôes acerca de sua eficácia, investigouse se os entrevistados acreditavam que organizar protestos pelas redes sociais ou pela internet poderia ser melhor.

O Gráfico 2, a seguir, demonstra os resultados dessa pergunta, numa comparaçáo entre a pesquisa global e as respostas dos participantes dos protestos: 
66 | Conrado Pereda Minucelli e Rosana Katia Nazzari

Gráfico 02 - Organizar protestos pelas redes sociais ou pela Internet pode ser melhor? (em \%)

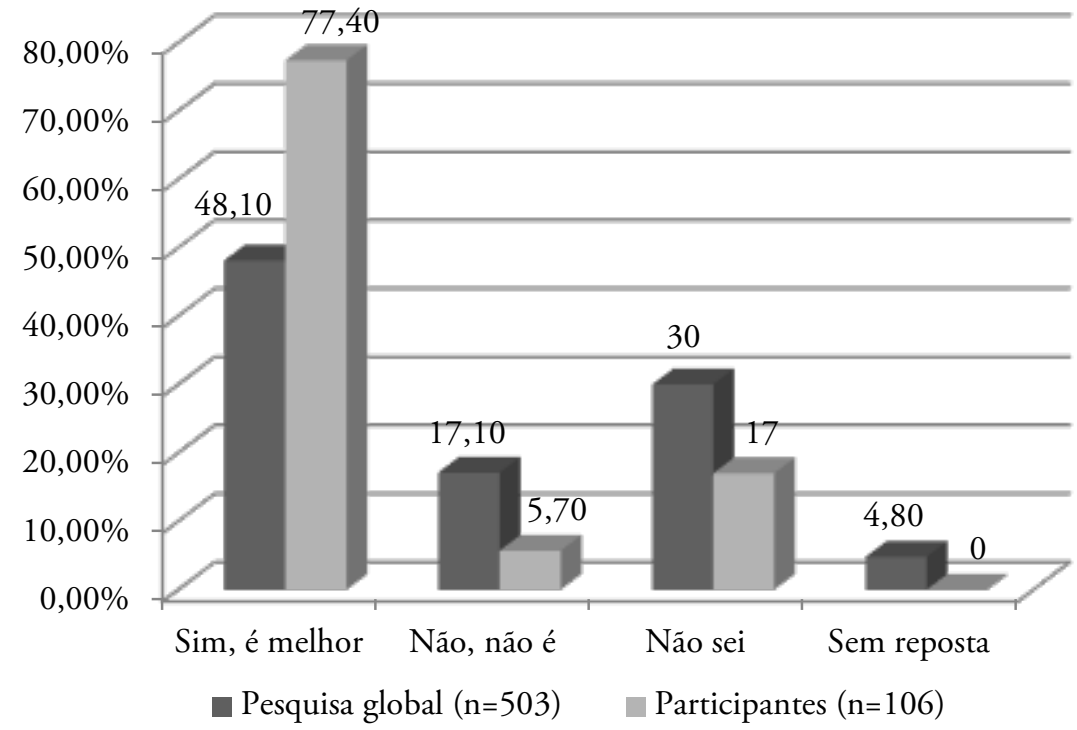

Fonte: Elaboração dos autores.

Infere-se, novamente, assim como na questão do posicionamento favorável ou contrário às mobilizaçóes, que o subgrupo de participantes dos protestos possui uma avaliação mais positiva em relação à influência das redes sociais no processo democrático, com uma diferença de $29,3 \%$ de respondentes que acreditam ser melhor organizar protestos de forma virtual.

Destaca-se que 30\% dos entrevistados, considerando a pesquisa global, não sabem responder se é melhor ou não, o que indica que o nível de informaçáo sobre os protestos e a experiência democrática proporcionada por eles, além de uma opiniáo acerca da organização, são diretamente relacionadas.

A dimensão teórica da organização, formação e possibilidades das comunidades virtuais de protestos, em conjunto com os resultados dos questionários, permite inferir que, do mesmo modo como a internet parece se constituir gradualmente como meio de informação, comunicaçáo e participação social, ela também se consolida como possibilidade de organizaçáo dos movimentos sociais e, especialmente, dos movimentos juvenis, que encontram caminhos ainda não totalmente descobertos para a superação da apatia política e dos índices ainda elevados de não participação na política. 


\section{Considerações finais}

Com destaque, pode-se afirmar que se vivenciou, com os movimentos em rede de Junho de 2013, no Brasil, a primeira experiência democrática de protestos, após o início do processo de globalização mundial, que utiliza, de forma majoritária, as redes sociais e a internet como principal meio de organização de protestos de rua, reivindicando pautas políticas, desde a derrubada de governos, em contraposição a ideias autoritárias, até o pedido por melhorias nos serviços sociais básicos.

Essa nova possibilidade de integração e diversidade evidenciou que os padróes nos comportamentos políticos dos cidadáos podem ser minimamente alterados em função da intensa disputa pelos rumos dos movimentos e, também, pela experimentação da noção de negociação pública do espaço político coletivo, estabelecendo os momentos dos protestos como momentos ricos de aprendizagem democrática e exercício dos direitos civis e da liberdade de expressão.

Pode-se apontar, portanto, que outra noçáo de democracia passa a ser concebida, por meio de algumas hipóteses como a substituição da relevância da representatividade institucional pela democracia direta e real e da tecnologia como facilitadora da construção, elaboração e avaliação das condiçôes reais de mobilização cidadã para este objetivo.

Esta ocasião aparenta proporcionar aos jovens novas formas de se interferir na arena política e de, por meio dos canais usuais de comunicaçáo da juventude contemporânea, imprimir no espaço público suas inquietaçóes e esperanças em relação à política, fazendo oscilar positivamente seus estoques de capital social e seus níveis de participação política, configurando, também, um momento de novas possibilidades para a cultura e socialização política juvenil.

Em meio a essas nuances, este estudo buscou analisar, com base na literatura clássica sobre o assunto e na aplicação de questionários quantitativos, as continuidades e descontinuidades dos processos de socialização, cultura e participação política da juventude e, especialmente, da juventude que frequenta estruturas de socialização, tais como a escola pública, tendo como ponto de partida os movimentos em rede.

Evidenciou-se, inicialmente, que as mudanças nestes processos passam pela forma que a atuação política para as mudanças sociais toma, pois, ao verificar o significante aumento de acompanhamento de notícias sobre política e sobre eleiçóes pela internet e pelas redes sociais, percebe-se que, após a experimentação democrática dos protestos, o interesse por esse tipo de informaçóes nos meios que é veiculado 
torna-se, em conjunto com o ciberespaço, um dos principais canais de comunicação dos jovens com o sistema político, seja para construir demandas ou para recepcionar açôes de governos e do Estado.

Somado a isto, nota-se que as informaçôes políticas nas redes sociais aparentam não ser relevantes apenas quando o jogo político democrático impóe a obrigação do voto, ou seja, apenas quando os procedimentos formais da democracia são analisados. Ao invés disso, ela se espalha cada vez mais nos caminhos virtuais e no tempo, estabelecendo uma relação cotidiana do jovem com a comunicação virtual dos acontecimentos e dos debates políticos.

Essa relação encontra, na avaliação dos jovens sobre a situação política do país e do município, um elevado descontentamento e uma continuidade nos significantes índices de desconfiança política e, especialmente, da desconfiança sobre as instituiçóes políticas representativas. Dessa forma, a percepção aferida do público da pesquisa é a de que o descontentamento caminha em paralelo a uma avaliação regular, ruim ou péssima das formas atuais da democracia.

Os traços autoritários encontrados nesta pesquisa, possivelmente, possuem, de igual forma, uma relação com os níveis de confiança política e confiança interpessoal dos jovens, visto que, de toda forma, as múltiplas variáveis que influenciam as formas de se pensar a vida social e política passam pelas instituiçóes sociais tradicionais, que admitem linhas de autoridade bem definidas e um poder tradicional e carismático marcantes na trajetória dos indivíduos. Tal associação pode se dar pelo fato de a família, a escola e a religiáo contribuírem para que estas linhas de autoridade se reproduzam no tempo e influenciem as orientações políticas.

No que se refere a estas instituiçóes, percebeu-se que há uma progressiva abertura democrática, relativamente maior que as anteriores, para a relativização de conceitos e práticas anteriormente tratadas como paradigmáticas, como a incapacidade dos jovens em participarem de decisóes no seio familiar, na gestão das escolas e na construção dos conceitos religiosos contemporâneos.

Em contraponto, este aumento nos níveis de confiança interpessoal e institucional não encontra, nos diferentes governos, o mesmo acréscimo; pelo contrário, eles foram decrescidos em relação a pesquisas anteriores, o que indica que a indignação pelos recorrentes casos de deturpação dos fins de um governo é destacada e expressada por meio dos ainda altos índices de desconfiança e, ainda, possivelmente, explica a elevada recusa das formas tradicionais da institucionalidade, como os partidos, no interior das manifestaçóes em rede. 
No entanto, a experimentação democrática dos protestos possibilitou que se mudassem, em curto prazo, alguns dos elementos que constituem as bases para o investimento de mais capital social pelos jovens estudados. Percebeu-se, por exemplo, que os sentimentos em relação à eficácia da participação política dos jovens aumentaram em relação a menos de cinco anos anteriores à pesquisa, indicando que, em conjunto com outros fatores, os protestos colaboraram, mesmo que de forma ainda não definitiva, para que houvesse um redimensionamento das visóes de mundo que constroem os jovens sobre suas próprias açôes nos espaços públicos democráticos.

A participação nos protestos, além de se configurar como um momento de relevante reflexão política, consolida, gradualmente, neste contexto, as redes sociais e a internet como fomentadoras do debate político, da discussão de ideias e posiçôes na arena política e, acima de tudo, como demonstrou a pesquisa, colaborou consideravelmente na mudança de algumas formas de pensar a política e no aumento do interesse em participar entre os que vivenciaram este processo.

Conrado Pereda Minucelli é Mestre em Ciências Sociais e Professor Assistente da Universidade Estadual do Oeste do Paraná (Unioeste). E-mail: cpminucelli@uol.com.br.

Rosana Katia Nazzari é Doutora em Ciência Política e Pósdoutora em Educação. É Professora Associada da Unioeste. E-mail: knazzari@hotmail.com.

\section{Referências}

ALMOND, Gabriel.; VERBA, Sidney. The Civic Culture: political attitudes and Democracy in five nations. Boston: Little, Brown and Company, 1965.

ALMOND, Gabriel; POWELL JR., G. Bingham. Uma teoria de politica comparada. Rio de Janeiro: Zahar Editores, 1972.

BAQUERO, Marcelo et al. Democracia, juventude e capital social no Brasil. Porto Alegre: Editora da UFRGS, 2004.

BARBETTA, Pedro Alberto. Estatística aplicada às Ciências Sociais. 5. Ed. Faculdade de Ciências Econômicas de Vitória (FACEV): Editora UFSC, 2002.

BILL, James; HARDGRAVE JR, Robert. Comparative politics: the quest of theory. Colombus: Bell \& Howell, 1973. 
CASTELLS, Manuel. Redes de indignação e esperança: movimentos sociais na era da internet. Rio de Janeiro: Zahar, 2013. . A sociedade em rede. São Paulo: Paz e Terra, 1999.

LATINOBARÓMETRO. Banco de dados do Latinobarômetro. Disponível em: <http://www.latinobarometro.org/>. Acesso em: 12 mar. 2014.

LÉVY, Pierre. Cibercultura. São Paulo: Editora 34 Ltda., 1999.

MINUCELLI, Conrado Pereda. Participação, cultura e socialização política juvenil em Cascavel/PR: um estudo a partir dos movimentos em rede. Em dissertação. Programa de Pós-Graduação Stricto Sensuem Ciências Sociais: Universidade Estadual do Oeste do Paraná/Campus Toledo, 2015.

MISZTAL, Bronislaw. Trust in modern societies: the search for the bases of social order. Printed in Great Britain, Polity Press: Cambridge, 1998.

MOISÉS, José Álvaro. Democracia e Confiança - Por que os Cidadãos Desconfiam das Instituiçôes Públicas?. São Paulo: Editora da Universidade de São Paulo, 2010.

NAZZARI, Rosana Katia. Juventude brasileira: capital social, cultura e socialização política. Cascavel: Edunioeste, 2006.

. Empoderamento da juventude no Brasil: capital social, família, escola e mídia. Cascavel: Coluna do Saber, 2006.

POSTMAN, Neil. O desaparecimento da infância. Rio de Janeiro: Graphia, 1999.

PUTNAM, Robert. Comunidade e Democracia: a experiência da Itália moderna. $5^{\circ}$ Ed. Rio de Janeiro: Editora FGV, 2006.

SARTORI, Giovanni. Comparación y método comparativo. In: SARTORI, Giovanni.; MORLINO, Leonardo. (org.) La comparación en las ciências sociales. Madrid: Alianza Editorial, 1994.

SCHERER-WARREN, Ilse. Dos movimentos sociais às manifestaçóes de rua: o ativismo brasileiro no Século XXI. Rev. Política \& Sociedade - Florianópolis, v. 23, n. 28, 2014.

SCHMIDT, João Pedro. Juventude e política nos anos 1990: um estudo da socialização política no Brasil. Em tese de Doutorado em Ciência Política. Universidade Federal do Rio Grande do Sul, 2000.

TATAGIBA, Luciana. 1984, 1992 e 2013. Sobre ciclos de protestos e democracia no Brasil. Rev. Política \& Sociedade - Florianópolis, v. 23 - n. 28, 2014.

THOMAZINI, Thais Rocha. Programa Câmara Jovem: limites e possibilidades de um processo de socialização política. Em dissertação. Programa de Pós-Graduação Stricto Sensu em Ciências Sociais: Universidade Estadual do Oeste do Paraná/Campus Toledo, 2012.

Texto recebido em 15 de abril de 2016. Aprovado em 25 de julho de 2016. 